\title{
Photography between Affective Turn and Affective Structure
}

\section{Introduction}

In Camera Lucida, still a major reference for emerging branches of photography theory, Roland Barthes paved the way for thinking about photography in terms of affect. In this late work, marked by grief for the loss of his mother, Barthes seems to have left his earlier semiotic work on photography behind and approached photographs through "an affective intentionality" that views photographs as immersed in affective responses to them. ${ }^{1}$ Photography theory's recent embrace of the so-called affective turn in the humanities aims to follow the later Barthes at the expense of the kind of photography theory practiced under the influence of the earlier, semiotic Barthes. ${ }^{2}$ The affective turn thus turns away not only from looking at photographs as images with aesthetic indifference, but also partially from reading them critically as meanings. Overcoming critical photography theory's exclusion of affect thus entails a move further away from the photograph in and of itself towards the various ways in which photographs and photographic practices incite affective responses that are themselves entangled in the often complex social realities in which these affects are felt.

In this article, however, I attempt to examine the photographic affect precisely from the perspective left aside by photography theory's affective turn. The question I will be asking is the following: Is there an affectivity of the photograph "itself", an affectivity inscribed in its semiotic structure and the aesthetic appearance that it produces? By talking about photography "itself" and its aesthetic appearance I do not intend to return to a modernist formalism or - even worse - an academic aestheticism. In order to tackle the question asked, I will rather go back to the way photography theory, inspired by the semiotic Barthes,

Roland Barthes, Camera Lucida: Reflections on Photography, trans. Richard Howard, Hill and Wang, New York 1981, p. 21.

2 Elspeth H. Brown and Thy Phu, "Introduction”, in Elspeth H. Brown and Thy Phu (eds.), Feeling Photography, Duke University Press, Durham 2014, pp. 2-3. 
had already incorporated thinking about the affectivity of photography before Camera Lucida was even published. Specifically, I have in mind a 1978 article in October, in which Thierry de Duve argues that "photography is probably the only image-producing technique that has a mourning process built into its semiotic structure, just as it has a built-in trauma effect." ${ }^{3}$ De Duve clearly distinguishes the immanent affectivity of photography from the way a photograph might affect its spectator as a result of its content (images of traumatic scenes) or personal sentimental value (photographs as substitutive objects). Rather, the affectivity built into the semiotic structure of the photograph is a result of its "indexical nature," i.e. the fact that "the referent of an index cannot be set apart from its signifier." The immanently affected structure of photography is thus understood semiotically in the manner proposed by the earlier Barthes. De Duve's approach will help us move away from the focus on the (personal, even if socially contextualised) affective experiences of the spectator suggested by Barthes himself in Camera Lucida and often taken up by affect theory. But it will also allow us to see more clearly how the later Barthes's own reflections on the photographic affect are conditioned by his previous semiotic focus. It is after all the specificity of photography as a medium that determines, according to Barthes, the way photographs affect us. Barthes's affective phenomenology thus rests on a structure that is itself affected.

Yet, the goal of this article is not only to return from affective phenomenology to affective structuralism. It is also to rethink the photographic affect by shifting the focus from indexicality to another feature of photography's structure: the way the camera captures a spatio-temporal fragment, isolated from the temporal and spatial continuum as well as the symbolic and imaginary frameworks in which the referent might be involved at the time of the shot. To a certain extent, this contradicts the direct link to the uniqueness of the referent and gives the photographic image a character of indeterminacy otherwise associated with autonomous aesthetic appearance. The aesthetics I have in mind here, however, is not the Greenbergian modernism that has often been the framework for incorporating photography into artistic discourses. Instead, I will approach the aesthetic dimension of the photographic image through Jacques Rancière's account of pho-

3 Thierry de Duve, “Time Exposure and Snapshot: The Photograph as Paradox", October 5 (Summer, 1978), p. 123.

4 Ibid. 
tography within the conceptual framework of what he calls the aesthetic regime of art. The structure of photography, I will argue, produces a specific type of aesthetic appearance, which has more to do with indeterminacy than indexicality.

This brings me to the second and central question of this article: If there is indeed an affect inscribed in the photographic type of aesthetic appearance, what kind of affect is it? As suggested by both Barthes and de Duve, it has to do with dealing with loss. Even though photography is distinguished from other types of images by providing an authentication of presence, its presence is necessarily a presence of loss. ${ }^{5}$ The privileged relation of the photographic image to reality does not amount to the triumph of representation, but rather to a direct emanation of a past reality, evidence of "that-has-been." This peculiar dynamic between direct presence and evident loss produces an affective polarity, with poles shifting with regard to what is lost: the referent itself or the world it belonged to. In Barthes, we can see this polarity or ambivalence as an alteration between amazement and desire, on the one hand, and grief, mourning, and melancholy, on the other. There is a similar combination in de Duve, who juxtaposes the mourning process inherent to photography (which he also characterises as melancholic and depressive) with its traumatic (or manic) side.

Barthes's and de Duve's accounts of photography's affective polarity are clearly dependent on the indexical nature of photography. But what happens if we focus on indeterminacy instead? Below I will show how this move implies a different kind of affectivity of photography. First of all, indeterminacy endows photography with indifference in relation to the referent. Yet this indifference has its own effect on affective polarity. If loss is no longer tied to a unique referent, new distinctions begin to appear. Rather than amazement or trauma, which both block the process of symbolic or imaginary reinscription of what is seen, the photographic isolation of the object entails curiosity about the possible contexts or worlds this moment could have belonged to. Instead of the monolithic block of mourning and melancholy, which appear as synonyms in both Barthes and de Duve, a crucial distinction between the two conditions noticed by Freud

See Jay Prosser, Light in the Dark Room: Photography and Loss, University of Minnesota Press, Minneapolis 2005.

6 Barthes, Camera Lucida, pp. 85-89. 
can be taken into account. While mourning is always tied to a specific lost object, melancholy is a consequence of an indeterminate loss.

\section{From index to affect}

While Camera Lucida grasped photography through a strong new conceptual apparatus that subsequently proved to be vastly influential (especially the studium/punctum distinction), it simultaneously renounced any generalising theoretical ambitions, with its author claiming to be "interested in Photography only for 'sentimental' reasons." "As James Elkins has noted: "Camera Lucida is at the beginning of a flourishing interest in affect, feeling, and trauma in the art world, and that may be the best explanation of its staying power." ${ }^{8}$ Yet, the affective intentionality that governs the book's understanding of photography remains firmly attached to the direct relation between the referent and its representation. Unlike in any other system of representation, "in Photography I can never deny that the thing has been there."9 The causal relationship between the referent and its sign, along with the collision of presence and absence, is something that Barthes already developed in his earlier semiotic writings on photography, influencing Rosalind Krauss's conceptualisation of the indexical nature of photography published in October a year before de Duve, following Krauss, examined its affective implications in the same journal. In Camera Lucida, published two years after de Duve's article, Barthes drew his own affective conclusions from the photographic that-has-been.

While grief and mourning are most often brought up when addressing the affective side of Barthes's book, the affect that first strikes Barthes as inscribed in the very semiotic structure of photography is actually one of astonishment or amazement (étonnement). The primary affective reaction to photography is not a reaction to the loss it implies (the referent is no longer what it was when the photograph was taken), but to the unique representational presence it is able to provide. Yet, the emanation of a referent that is no longer there does not bring with it the past world it belonged to. Photography, as Barthes makes clear, does not resurrect lost time:

Ibid., p. 21.

8 James Elkins, What Photography Is, Routledge, New York 2011, p. xi.

9 Barthes, Camera Lucida, p. 76. 
The Photograph does not call up the past (nothing Proustian in a photograph). The effect it produces upon me is not to restore what has been abolished (by time, by distance) but to attest that what I see has indeed existed. Now, this is a strictly scandalous effect. Always the Photograph astonishes me, with an astonishment which endures and renews itself, inexhaustibly. ${ }^{10}$

If it is not the nostalgic yearning for the past that introduces loss to photography's presence, how does grief come to accompany amazement as the other side of photography's affective polarity? While amazement is a consequence of making what is lost to the past present, the actual loss photography implies is less oriented towards the past than it is to the future. This is also what distinguishes photography from cinema, which might have the same "indexical" relation to reality, but does not share its arrested temporality: "Like the real world, the filmic world is sustained by the presumption that, as Husserl says, 'the experience will constantly continue to flow by in the same constitutive style'; but the Photograph breaks the 'constitutive style' (this is its astonishment); it is without future (this is its pathos, its melancholy)." for Barthes, because what is astonishing about photography is precisely that it can keep the past present. Yet, the presence that it keeps comes at a price: it does not develop further, its future is lost.

The loss of the future is what makes time a punctum, i.e. what truly affects us when looking at photographs. While the first part of the book looks into the apparently insignificant details in a photograph that accidentally arouse our attention, the loss of the future is what brings to light this other kind of punctum, which ultimately makes photography a sign of death: "It is because each photograph always contains this imperious sign of my future death that each one, however attached it seems to be to the excited world of the living, challenges each of us." ${ }^{12}$ The way photography refers to the specific thing that has been in front of its lens also individualises our affective relations to it. A found photograph of Barthes's mother (the "Winter Garden Photograph") can thus become the central item of the book (or its central absence, since it is not reproduced).

\footnotetext{
$10 \quad$ Ibid., p. 82.

${ }_{11}$ Ibid., pp. 89-90.

$12 \quad$ Ibid., p. 97.
} 
This photograph of the mother he still mourns achieves for Barthes "the impossible science of the unique being" ${ }^{13}$ and it is with this same uniqueness that death addresses itself to every one of us through the photographs we come across. Astonishment thus makes way for grief and mourning - much more than for melancholy itself, as I will argue below.

In de Duve's account, photography's semiotic structure produces an affective duality similar to the one proposed by Barthes. The mourning/melancholy/grief complex remains in place (although de Duve adds depression to the list), while the positive affect of amazement that Barthes proposes as its other side is replaced by de Duve with the more negative composite of trauma and mania. De Duve also attempts to give a more precise conceptual status to both affective poles than Barthes. Following Freud, de Duve understands affect in terms of the allocation (cathexis or Besetzung) and withdrawal of libido to and from specific objects. ${ }^{14}$ But before we come to this, we should note that de Duve understands the affective duality of photography as linked to a split in its indexical nature.

In an almost dialectical fashion, de Duve understands photography as a contradiction between two constitutive and coexisting models of photography, models that are at the same time abstract (they cannot be empirically separated as two types of photography) and concrete (a clear description and examples are given of both). This contradiction is irresolvable and thus makes for a constitutive paradox of photography. ${ }^{15}$ The two models or ways of perceiving photographs are the time exposure, an example of which is the portrait, the funerary portrait in particular, and the snapshot, the prime example of which is press photography. While the time exposure is perceived as a picture, an autonomous representation, the snapshot is perceived as the pictured event itself. ${ }^{16}$ The two models engage two different relations between the referent and the image, as well as two different modes of temporality. Crucially, both are destined to miss out on what they aim for. The time exposure aims to preserve the referent, but

\footnotetext{
Ibid., p. 71.

${ }^{14}$ De Duve, “Time Exposure and Snapshot”, pp. 123-124.

15 Ibid., p. 125.

16 Ibid., p. 113.
} 
cannot help designate its death. Meanwhile, the snapshot actually manages to preserve an artefact of the event itself, but freezes the temporal fluency of life that it wants to convey. In turn, this fluency is captured by the time exposure as the temporality of the memory activated by the image. The time exposure and the snapshot thus fail at their own respective goals, but manage to achieve each other's: "Whereas the snapshot refers to the fluency of time without conveying it, the time exposure petrifies the time of the referent and denotes it as departed. Reciprocally, whereas the former freezes the superficial time of the image, the latter releases it." ${ }^{17}$

De Duve considers the snapshot to be traumatic, since it blocks any attempt to resolve what we see by symbolising it. The encounter with an artefact of the event renders us "momentarily aphasic" and prevents us from including it in any kind of narrative. ${ }^{18}$ The frozen movement of the event splits the present moment it attempts to capture: we are always too early to witness the resolution of what is going on in the image, but also too late to witness or intervene in the depicted situation. ${ }^{19}$ In a certain sense, the photograph brings us too close to the event, the thing itself, at the expense of the narrative context or symbolic framework the event was inscribed in. In other words, we get a hold of the object (an image of the referent as it was at a crucial moment in time and space), but lose the world it was a part of (due to the continuous nature of time and space). The time exposure, on the other hand, stimulates speech instead of blocking it. The captured moment in time encourages the unfolding of "a narrative that meshes the imaginary with the symbolic and organises our mediation with reality." ${ }^{20}$ The funerary portrait or the family photo album activate our memory and help us reconstruct periods of the portrayed person's life. They thus help us to regain the world in the context of which the photograph was taken, but at the price of the referent, which the photograph consigns to death. As such, the time exposure lends itself to what Freud called the work of mourning: the photograph functions as a substitutive object that ultimately helps us accept the loss and reinvest our libidinal energy into other objects. It is in this sense that "there is something like a mourning process that occurs within the semiotic structure

\footnotetext{
Ibid., p. 116.

Ibid., p. 119.

Ibid., pp. 119-121.

Ibid., p. 121.
} 
of the photograph."21 The primary opposition between trauma and mourning is then generalised by de Duve as the "unresolved oscillation between two opposite libidinal positions: the manic and the depressive." ${ }^{22}$ In the conclusion of the text, he simply equates mourning with melancholy and depression, even though he quotes Freud's "Mourning and Melancholia", a text that explicitly deals with the difference between the two conditions it mentions in the title.

For both De Duve and Barthes, the affective polarity of photography ultimately tips to the side of loss as the primary factor. The opposite resolution is also possible, of course, as testified to by, among others, Shawn Michelle Smith's discussion of F. Holland Day's photography through the Barthesian affective intentionality. Emphasising desire instead of grief, Smith argues for "a punctum of pleasure"23 to supplement the punctum of death. By unveiling the queer dimension of Barthes's conceptual framework, Smith shows how the indexical nature of photography allows one's desire to "find a beyond that is proximate, an absence that is present, something desired that can be attained - and that is the ecstasy of photography". ${ }^{24}$

Another version of the ecstatic punctum is proposed by Serge Tisseron in his psychoanalytic account of photography as not only an image but also a practice. Stepping away from the indexical nature of photography, Tisseron argues that photography theory should shift its focus from the "that-has-been" of the represented object to the "that-was-lived" of the photographer. ${ }^{25}$ Taking a picture not only freezes a moment in time, cutting it off from the continuity of the world, but also affirms the connection between the photographer and the world in a moment of ecstatic participation. ${ }^{26}$

\footnotetext{
${ }^{21} \quad$ Ibid., p. 123.

22 Ibid., p. 124.

23 Shawn Michelle Smith, "Photography between Desire and Grief: Roland Barthes and F. Holland Day”, in: E. H. Brown and T. Phu (eds.), Feeling Photography, p. 43.

24 Ibid., p. 44.

25 Serge Tisseron, La mystère de la chambre claire: Photographie et inconscient, Flammarion, Paris 1996, p. 60.

26 Ibid., p. 169.
} 
Yet, tipping the affective balance from grief to bliss - as Smith and Tisseron do in different ways - is not the only way to challenge Barthes's affective affinities. In his book-length confrontation with Camera Lucida, James Elkins argues that Barthes's punctum, for all its emphasis on grief, misses what is truly painful about photography, namely its "non-humanist, emotionless side." ${ }^{27}$ Elkins replaces the combination of realism and affective phenomenology that governs Barthes's dealings with photography with what could be branded an impersonal materialist approach. What photography reproduces is not so much the reality of our experience of the world but all the material details that we otherwise ignore. If we look beyond the represented figures and situations that present themselves as meaningful to the spectator, what we see in a photograph is a collection of material details of little interest, the indifference of matter. Photographs show us "something about the world's own deadness, its inert resistance to whatever it is we may hope or want. Photography fills our eyes with all the dead and deadening stuff of the world, material we don't want to see or to name. ${ }^{28}$ Elkins thus proposes a more radical shift: instead of balancing the photographic experience between grief and astonishment, he presents it as an experience of the world's indifference to the subject's affective investments. By this kind of intrusion of peripheral details, the notion of the punctum is expanded but also made impersonal and thus completely undermined with regard to Barthes's definition.

\section{From indeterminacy to indifference}

The impersonality of peripheral details is at the centre of another account of photography that progresses through a critique of Barthes. For Jacques Rancière, photography's ability to register all sorts of material details that can lend themselves to potential apprehension as a punctum is not only a specificity of the photographic medium that sets it apart from art, but also what makes photography a part of the modern aesthetic revolution. In this sense, the aesthetic regime of art, which started to emerge even before photography was invented, was already "photographic". Due to its rejection of traditional hierarchies of noble and ignoble subjects and the higher and lower genres and styles that correspond thereto, it could treat anything as significant within the self-sufficiency

${ }_{27}$ James Elkins, What Photography Is, p. xi.

28 Ibid., p. xii. 
of aesthetic appearance. Photographs can thus be considered art "according to the aesthetic logic, because they do not owe anything either to the quality of their subject or to any artistic addition meant to raise them from their mediocrity. They owe it only to themselves. They are the testimony of a glance directed at the right time at the right spot to catch what is in front of it." ${ }^{29}$ The significance of the insignificant detail thus exceeds the meaning assigned to it by Barthes, but also suggests another kind of affectivity.

In his essay "The Pensive Image”, Rancière argues that Barthes's opposition between the studium and the punctum is a deeply flawed one, since both poles tend to collapse into a short circuit. ${ }^{30}$ Looking at Alexander Gardner's Portrait of Lewis Payne, Barthes defines the punctum as "he is going to die." ${ }^{31}$ Yet, as Rancière rightly points out, there is nothing in the picture itself that could tell us that the man in the photograph is sentenced to death. One could still argue that for Barthes any photograph is a sign of death, which entails that the death sentence of Lewis Payne is not necessarily what makes the spectator be affected by his death. But this would not change the fact that the punctum of time and death presupposes the indexical relation between the image and the person photographed. The photographic affect is thus "an affect produced directly on us by the body of the one who faced the lens." ${ }^{32}$ The direct line between the unique being that we see in the photograph and the way it affects us, Rancière suggests, lets studium back into what is supposed to be pure affectivity beyond knowledge.

For Elkins, Gardner's Portrait is, "just to be literal about it - an image of scratches and scrapes on iron sheets, with a figure interposed." ${ }^{33}$ Along with the figure, the whole drama of human finitude is dissolved in the indifferent matter of the background. For Rancière, on the other hand, this dissolution happens within the figure itself. What we see in the photograph is not the determinate

29 Jacques Rancière, Aisthesis: Scenes from the Aesthetic Regime of Art, trans. Z. Paul, Verso, London 2013, p. 209.

30 Jacques Rancière, The Emancipated Spectator, trans. G. Elliott, Verso, London 2009, pp. 107-132.

31 Barthes, Camera Lucida, p. 96.

32 Rancière, The Emancipated Spectator, p. 113.

33 Elkins, What Photography Is, p. 117. 
unique being, but a "tangle between several forms of indeterminacy." ${ }^{34}$ Nothing in the photograph can tell us that the man is sentenced to death, but even if we knew that, we could not penetrate the thoughts hiding behind his pensive gaze. Rancière uses his own example, a portrait by Rineke Dijkstra, to show that the presence of the photographed figure in general is "that of the ordinary being, whose identity is unimportant, and who hides her thoughts in offering up her face." ${ }^{35}$ Such indeterminacy defines the image as "pensive", not only because we are unaware of the portrayed person's thoughts, but because thought in the image ceases to be linked to the story of the unique being. The image is pensive because it "contains unthought thought, a thought that cannot be attributed to the intention of the person who produces it and which has an effect on the person who views it without her linking it to a determinate object." ${ }^{6} 6$ The immanent thought of the image emerges precisely where the relation between the creator, the referent, and the spectator's response is interrupted.

Instead of focusing on the indexical nature of photography, Rancière emphasises another leitmotiv of photography theory, namely the way photography captures a framed moment, cut off from the continuum of time and space. As Sigried Kracauer pointed out (in reference to a well-known passage in Proust's In Search of Lost Time in which the narrator sees his grandmother as in an unflattering snapshot), photographs are fragments, whose meaning remains undetermined as they are isolated from the symbolic, imaginary, or affective contexts in which they were taken. ${ }^{37}$ Their referents now remain objects that have lost their worlds, although this does not necessarily make them ruins. Rancière enables us to see indeterminacy in a more productive light: instead of its lost contexts, which it was supposed to express, we can see the image as a self-sufficient aesthetic appearance, as a sensory event in its own right.

This does not make the photographic image any less realistic, however. With its focus on the ordinary and the marginal, ignoring the traditional hierarchy of subjects and genres, realism, for Rancière, is a founding pillar of the aesthetic regime. The aesthetic indifference that emanates from the indeterminacy of the

34 Rancière, The Emancipated Spectator, p. 114.

35 Ibid., p. 116.

36 Ibid., p. 107.

37 Sigfried Kracauer, The Past's Threshold: Essays on Photography, trans. C. Joyce, Diaphanes, Zurich 2014, pp. 73-74. 
photographic image is not a result of aesthetisation, but of the impersonal gaze of the camera that indifferently registers what is in front of the lens. This is also why, as Rancière recalls, Walker Evans could cite Flaubert as a major influence on his documentary photography. The aesthetic quality of realism in literature or photography is not a matter of "an artistic addition to the banal," but, on the contrary, of "a deletion: what the banal acquires in them is a certain indifference," achieved by the removal, from what they portray, of "what makes it the mere expression of a determinate situation or character." ${ }^{8} 8$

What are the affective consequences of the move from indexical uniqueness to the indeterminacy of impersonal life? Do we end up dissolving both astonishment and grief in plain indifference? As I have discussed elsewhere, Rancière follows Hegel in showing how aesthetic indifference does not entail an absence of affect but is affective and affected in its own right ${ }^{39}$ Artworks confront us like the blessed gods of Olympus, Hegel claimed, blessed precisely in their complete indifference to the mortal world. Yet, as Rancière points out, Hegel rediscovers such bliss in the pensive gaze of a figure portrayed by Raphael and the delight of beggar boys in Murillo's genre paintings. ${ }^{40}$ The indifferent appearance, even of insignificant realistic figures, thus generates its own affectivity.

But if mania transforms into this kind of blissful or pensive appearance, what should we make of its traumatic side? In the essay "The Intolerable Image", which appears in the same book, Rancière repeats his argument against the direct connection between the referent of the image and its affective power, which is often presupposed by the discourse surrounding politically charged photography. ${ }^{41}$ In this context as well, Rancière considers the effects of indeterminacy. Discussing Sophie Ristelhueber's landscapes of conflict-torn areas, he praises the photographs for shifting the focus away from the emblems that most directly express conflict, to the landscapes where the conflict can be seen without anticipating the meaning and effects of the image: "In this way, she perhaps effects a displacement of the exhausted affect of indignation to a more discreet

38 Rancière, The Emancipated Spectator, pp. 118-119.

39 Rok Benčin, “Art Between Affect and Indifference in Hegel, Adorno, and Rancière”, Filozofski vestnik 40 (1/2019), pp. 165-182.

$4^{0}$ Rancière, Aisthesis, pp. 21-37.

${ }_{41}$ Rancière, The Emancipated Spectator, pp. 83-105. 
affect, an affect of indeterminate effect - curiosity, the desire to see closer up." ${ }^{\prime 2}$ This affective shift does not make the image any less "real". For Rancière, it is a way of politically activating the very pensiveness and indifference of aesthetic appearance instead of relying on the transfer of a political message through the direct line between intention, referent, and reception.

\section{From mourning to melancholy}

What remains to be seen is what the indeterminacy of photography entails for the other side of its affective polarity. What happens to the affective block of grief, melancholy, mourning, and depression that more or less merge together in Barthes and especially de Duve? Saying that he ignores any difference between these negative affects would nevertheless be unfair to Barthes, especially considering his remark in Camera Lucida about his inability to turn his grief into mourning. ${ }^{43}$ Indeed, Freud presents melancholy as unsuccessful mourning, the inability or refusal to detach from the lost object. This is the reason why Jay Prosser claims that melancholy instead of mourning (corresponding to Freud's distinction) is the central photographic affect in Camera Lucida. ${ }^{44}$ But there is a perhaps more crucial difference between mourning and melancholy identified by Freud, which comes to light precisely with respect to the either determinate or indeterminate nature of the loss that has caused the condition. In mourning, the lost object is determined and unique, while in melancholy it is no longer apparent to the subject what has even been lost. Even if the determinate lost object that induced the condition can be identified, the melancholic still does not know what he or she has lost with that object. ${ }^{45}$ From this perspective, melancholy is no longer defined only by the inability or refusal to give up the lost object due to its irreplaceable uniqueness. It is also distinguished from mourning by the nature of the lost object, which is now marked by radical indeterminacy. From this perspective, the focus on the unique being makes Barthes's approach foreign to melancholy. The shift from indexical uniqueness to indeterminacy thus enables us to account for the affective difference that mattered to Freud

42 Ibid., p. 104. See also Rok Benčin, “Art Between Affect and Indifference”, pp. 181-182.

43 Barthes, Camera Lucida, p. 90.

44 Prosser, Light in the Dark Room, p. 23.

45 Sigmund Freud, "Mourning and Melancholia", in The Standard Edition of the Complete Psychological Works of Sigmund Freud, Volume XIV, trans. J. Strachey, The Hogarth Press, London 1957, p. 245. 
but became blurred in affective accounts of photography. Grief and mourning are affects related to a specific lost object, the unique being that emanates indexically through photography. Melancholy and depression, on the other hand, are affects of indifference, not only in relation to the world seen under the sign of the lost object, but also in relation to the lost object itself, which becomes indeterminate.

Taking this into account, how are we to understand the shift from indexicality to indeterminacy in terms of photography's paradoxical structure theorised by de Duve? To recall, the snapshot aims to capture the flow of life only to obtain a seemingly artificial artefact cut off from temporal and spatial continuity. Time exposure, on the other hand, manages to capture its object as it wants it, but only to immediately consign it to death, which in turn enables the spectator to reminisce and commemorate the past. While the snapshot aims at capturing the world but provides a worldless object, which causes trauma and mania, the time exposure aims at capturing the object but ends up reconstructing a world whose central object is lost, inducing mourning, melancholy, and depression. Both sides, however, produce their effects based on indexicality, the image's relation to the unique referent, be it a snapshotted moment or an exposed being. If we focus on indeterminacy instead of on indexicality, however, the affective ambivalence reverses its poles with regard to the snapshot and the time exposure. As we have already seen, portraits or landscapes whose identity is unimportant are pensive exposures that make us wonder about the worlds they might have been taken in. Outside the family album, where no specific past to be reconstructed is anticipated, memory makes way for curiosity and imagination. With their self-sufficiency as appearances, they are not signs of depression, but radiate an affected indifference as pensiveness or bliss.

Snapshots, on the other hand, can be seen as melancholic insofar as they capture moments of worlds at the point of bifurcation. We can see the captured moment, but we do not know exactly what world it was taken in. Yet, instead of a manic attempt to capture the real movement of the exact world in question, an attempt doomed to fail, we can see it as a melancholic desire for the possible worlds which this moment is simultaneously opening and closing: opening because the moment - as artificially isolated by the photograph - is infused with potentiality, and closing because we have no access to these potentialities and know that most of them necessarily remain unrealised. What makes snap- 
shots melancholic is therefore the way they are cut out from their worlds, i.e. the symbolic and imaginary frameworks that provide the multiple contexts in which these moments could be made meaningful. But the loss of these specific contexts to which the referent belonged can also be seen as a gain: the true melancholic lost object is the indeterminate possible worlds to which the moment, isolated by the photograph, could have belonged. The possible worlds evoked by the photograph may be lost, but are obviously also generated by melancholy: they only exist as a fiction for the melancholic gaze. ${ }^{46}$ Yet, such fictions are only made possible by the indeterminacy of the photographic image itself, its immanent pensiveness.

In contrast to melancholy, depression - in terms of photography - could be understood as the complete failure of such a fictional gaze, the inability to reconnect the meaningless image to anything symbolic or imaginary. This is what happens to Proust's narrator when he sees his beloved grandmother the way a photographer could have seen her: as "a dejected old woman whom I did not know." disturbing in its indifference, could be understood as a generalisation of this “depressive” way of seeing photography.

\section{Conclusion}

This article started as an attempt to retreat from the affective phenomenology proposed by Barthes and taken up by the affective turn in photography theory to what - following de Duve, but also Barthes himself to a certain degree - could be called the affective structuralism of photography. This allowed us to move beyond the content of photographs and the affective conditions of their creation and reception to the affectivity inscribed into the very structure of photography as a medium. Yet, we proceeded to challenge the assumption common to both the earlier and the later Barthes: that the photographic affect is both structur-

46 Here, I am relying on Giorgio Agamben's argument on the imaginary nature of the lost object in melancholy. See Giorgio Agamben, Stanzas: Word and Phantasm in Western Culture, trans. R. L. Martinez, University of Minnesota Press, Minneapolis 1993, p. 25.

47 Marcel Proust, The Guermantes Way, trans. C. K. Scott Moncrieff, http://gutenberg.net.au/ ebooks03/0300411.txt (last accessed: 30 November 2020). I discuss Proust in relation to photography from a more "melancholic" perspective in Rok Benčin, "Proustian Developments: The World and Object of Photography”, SubStance 46 (3/2017), pp. 16-30. 
ally and phenomenologically determined by its indexical nature, the direct link between the image and the uniqueness of its referent. Instead of focusing on indexicality, we have thus followed the implications of another characteristic of the photographic image, its indeterminacy, which is a consequence of the way the camera captures a moment and isolates it from the temporal and spatial continuum as well as the symbolic and imaginary frameworks that could otherwise provide the referent's contextual meanings. This shift in focus alters the affective spectrum that can be discerned within the structure of photography. Beyond the astonishment, trauma, and mania associated with the reappearance of a specific referent in photographs, it allows us to see in it a certain indifference, characteristic of pure aesthetic appearance in which ties with the referent are cut. Such indifference, as we have seen, is itself affected, either as the pensiveness of the incomplete or the bliss of the self-sufficient. On the other side of the spectrum, it allows us to distinguish between mourning and melancholy, the former being linked to an identifiable lost object that left an indexical trace in the image, while the latter's loss is of an indeterminate object that evokes the possible worlds it might have belonged to.

Breaking the straight line from index to affect thus taps into a different kind of affectivity within the photographic structure. This way, Barthes's emphasis on loss is not countered by moments of ecstatic desire or participation in the world, but by a different kind of loss. If the loss is not of a determinate object or world, it becomes productive in the sense of producing fictions of what the loss might have been. Yet, the point is not to redeem potentiality as a value in and of itself, but rather to see it actualised in worldless objects and objectless worlds that disrupt the narrative temporality that assigns objects to their proper worlds and worlds to their proper objects.

\section{References}

Agamben, Giorgio, Stanzas. Word and Phantasm in Western Culture, trans. R. L. Martinez, University of Minnesota Press, Minneapolis 1993

Barthes, Roland, Camera Lucida. Reflections on Photography, trans. Richard Howard, Hill and Wang, New York 1981

Benčin, Rok, “Art Between Affect and Indifference in Hegel, Adorno, and Rancière”, Filozofski vestnik 40 (2019), No. 1 
- "Proustian Developments: The World and Object of Photography", SubStance 46 (2017), No. 3

Brown, Elspeth H. and Thy Phu, "Introduction”, in Feeling Photography, ed. Elspeth H. Brown and Thy Phu, Duke University Press, Durham 2014

de Duve, Thierry, “Time Exposure and Snapshot: The Photograph as Paradox”, October 5 (Summer, 1978), pp. 113-125

Elkins, James, What Photography Is, Routledge, New York 2011

Freud, Sigmund, "Mourning and Melancholia”, in The Standard Edition of the Complete Psychological Works of Sigmund Freud, Volume XIV, trans. J. Strachey, The Hogarth Press, London 1957, pp. 243-158

Kracauer, Sigfried, The Past's Threshold. Essays on Photography, trans. C. Joyce, Diaphanes, Zurich 2014

Prosser, Jay, Light in the Dark Room. Photography and Loss, University of Minnesota Press, Minneapolis 2005

Proust, Marcel, The Guermantes Way, trans. C. K. Scott Moncrieff, http://gutenberg.net. au/ebooks03/0300411.txt (last accessed: 30 November 2020)

Rancière, Jacques, Aisthesis. Scenes from the Aesthetic Regime of Art, trans. Z. Paul, Verso, London 2013

- The Emancipated Spectator, trans. G. Elliott, Verso, London 2009

Smith, Shawn Michelle, "Photography between Desire and Grief: Roland Barthes and F. Holland Day", in Feeling Photography, ed. Elspeth H. Brown and Thy Phu, Duke University Press, Durham 2014

Tisseron, Serge, La mystère de la chambre Claire. Photographie et inconscient, Flammarion, Paris 1996 